\title{
Quality of Institutions in the European Union countries. Application of TOPSIS Based on Entropy Measure for Objective Weighting
}

\author{
Adam P. Balcerzak \\ Nicolaus Copernicus University in Toruń, Department of Economics, ul. Gagarina \\ 13a, 87-100 Toruń, Poland, e-mail: adam.balcerzak@umk.pl
}

\begin{abstract}
The relation between the quality of institutions and long term growth is currently an accepted stylized fact, which has good support in empirical literature with regard to both developing and developed countries. In the case of the second group, the quality of intuitions is crucial for keeping their abilities to face quick technological changes, which is a condition for maintaining their international competitiveness. The objective of the article is to analyse the quality of institutions in the European Union countries in the years 20002015 from the perspective of its influence on the speed of resources reallocation. The research touches upon the question of the abilities of the countries to take advantage of the knowledge based-economy potential. The concept of the institutional quality is rooted in the transaction costs theory framework. The phenomenon under evaluation is treated as a multiple-criteria problem. Thus, modified TOPSIS method based on entropy measure for objective weighting is applied here. The research shows institutional disparities between Northern and Southern European countries and confirms significant institutional reforms implemented in the Central European economies, which resulted in an improvement of their institutional quality with regard to knowledge-based economy requirements.
\end{abstract}

Keywords: quality of institutions; European Union; entropy measure; multiple-criteria analisis; TOPSIS

\section{Introduction}

Development of new institutional economics, with its empirical contribution to the growth theory, has significantly influenced mainstream economics for the last twenty years. The standard assumption of exogenic character of institutions, which is typical for both exogenous and endogenous growth models, is usually not accepted any more, especially in the case of policy-making implications and objectives. It is currently commonly assumed that the quality of institutions with their ability to transform under the influence of fundamental changes of economic conditions is crucial for long-term growth. Thus, both formal and informal 
institutions affecting not only legal, but also the political and social environment, have a significant influence on the well-being of societies. However, this commonly accepted idea is constantly faced with both theoretical and practical problems. From both perspectives, the fundamental dilemmas of institutional economics relate to problems of definition and measurement of institutional quality, which have not only a multivariate but often also a latent character. From the policy perspective, the variety of institutional arrangements, which are the result of historical and culture long term formation process, indicate that many institutional factors of fundamental importance are very difficult to change or copy from one society to another $[1,2,3,4]$. Therefore, from the policy guidelines perspective, special attention should be given to formal institutional factors influencing growth incentives, which can be modified in a medium or shorter term. These institutions are in the main scope of the article.

The objective of the current article is to analyse the quality of institutions in the European Union countries in the years 2000-2015. The research concentrates on the institutional aspects that are of crucial importance for the process of reallocation of resources in the case of relatively developed countries in the reality of knowledge-based economy, and which can be modified in a relatively short time. The main common characteristic of the analysed institutional aspects is their influence on the speed of reallocation of the economic resources to potential new applications. The definition of quality of institutions is based on the postulates of the transaction cost theory. The current research is a continuation of the Author's previous studies [5], which aimed at evaluation of the progress obtained by new member states of the European Union in reforming their institutions under the pressure of global financial crisis. In that research, a modified TOPSIS method was applied, based on the assumption of equal importance of all institutional aspects which form the phenomenon under evaluation. On the other hand, in the current article not only the times-pan of the study was extended, but based on recent research the specifics of the applied aspects were redefined. Additionally, the assumption of equal importance of all institutional aspects was removed.

The paper is structured as follows: first of all, a theoretical background and literature review for the research is given. In that part, special attention was paid to previous studies on institutional growth determinants, which are related to developed countries. Then, the measurement problems with regard to the quality of institutions and their implications for the current research are presented. In the next section, a specific description of methodological approach is done, which enables to replicate its results. Finally, the empirical results and their discussion are given. The article ends up with conclusions, ideas on possible future research and applications of the obtained results. 


\section{Literature Review}

\subsection{Crucial Institutional Aspects in Developed Countries under Knowledge-based Economy}

In recent years institutional researchers have concentrated on a wide spectrum of factors such as institutions of governance (which guarantee contract enforcement), formal and informal institutions that can be transformed in different time-spans, and finally, many methodological approaches applied in the field [6, 7, 8, and 9]. Based on these directions of studies, it can be stated that current institutional research must be based on precise selection of institutional aspects, and the scope of the research must be narrowed to provide both theoretical results and policy implications.

The objective of this section is to provide theoretical framework and empirical background for selection of institutional aspects that are crucial for developed countries with regard to supporting their growth potential in the reality of an opened highly competitive knowledge-based economy.

Based on the current state of the art with regard to new institutional economics, it is commonly accepted that the influence of institutions is attributed to both supply and demand side of economy. In the first case, it is mostly related to supporting growth of capital, then improving conditions for technological progress, which finally can influence labour and productivity growth. On the demand side, effective institutions can support a long-term level of investments. In the reality of knowledge-based economy, the factors influencing the speed of technological progress and technological change are of the highest importance. As a result, in the case of developed countries the crucial role should be given to all institutional factors that can affect the speed of transformation of resources to high productivity allocations. The importance of this factor is of universal character and can be attributed to economies at any level of development and any time perspective. However, in the case of developed economies in the reality of quick technological changes its role is unprecedented. Therefore, it will be the core of further analysis.

Based on the previous studies of the Author, which have been concentrated on the determinants of productivity changes in developed countries since the mid-1990s [5], there are five crucial institutional areas which can have a dominant role for developed economies in the process of reallocation of resources in the reality of knowledge-based economy:

1) Formal regulations influencing entrepreneurship;

2) Effectiveness of juridical system in keeping a low level of transaction costs and supporting the effectiveness of market mechanism; 
3) Regulations affecting competitive pressure;

4) Effectiveness of labour markets;

5) Financial markets institutions as a stimulation of development of enterprises with high growth potential.

The role of entrepreneurial activity and its influence on supply of high-growth firms, which in the cumulative process contribute to the macroeconomic productivity dynamics have been the object of intensive research since the mid1990s [10]. Within this framework, the significant role of institutional arrangements on entrepreneurial activity with regard to innovative start-ups and its macroeconomic consequences based on the Swedish case was analysed by Davidsson and Henrekson [11], where the authors argue that the basic prerequisite for the emergence of a sizable number of high growth enterprises, which in turn brings positive macroeconomic results, is that the key industries and sectors of the economy are available for entrepreneurial exploitation. Therefore, the minimum number of entry barriers and low entrepreneurial transaction costs are of basic importance. In the recent research, Bosma et al. [12] have tested econometrically the relations between institutions, productive entrepreneurship and economic growth for 25 European economies. Their paper confirms that in the case of the EU countries, productive entrepreneurship contributes to economic growth, where proxies for quality of institutions, financial stability, small government, and perceived start-up skills were the most important predictors of productive entrepreneurship. The strong interdependence between entrepreneurial innovation and regulatory efficiency for the European Union economic growth determined by institutional factors has also been recently confirmed by Ignatov [13]. However, these results can be expanded internationally further. Aparicio et al. [14] analysed panel data with 43 countries in the years 2004-2012 with regard to institutional factors that encourage opportunity entrepreneurship in order to achieve higher rates of economic growth. They showed that informal institutions may have a higher impact on opportunity entrepreneurship than formal institutions.

The relation between the effectiveness of judicial system and long-term economic growth is currently undisputed. The quality of judicial system determines protection of property rights and low transaction cost in the process of contracts enforcement. Thus, it encourages savings and investments [15]. Based on the case of Italy, Lorizio and Currieri [16] show how the quality of legal system impacts fundamental dimensions of development, such as optimal allocation of resources, which finally influences productivity. They argue that economic disincentives arising from the failure of justice result in contraction of start-ups, the preference for keeping small-size enterprises, which affects negatively the competitiveness of the national production system and its low productivity, finally a lower level of investments and the phenomenon of freezing capital.

The next institutional aspect under consideration relates to internal competitive pressure in the economy, which also further affects its international 
competitiveness. The internal competitive intensity is highly dependent on microand macroeconomic regulations influencing transaction costs and barriers to entry. Both sectorial and macroeconomic comparative research, which have been done since the mid-1990s, have confirmed that competitive pressure affected by national regulations can significantly form incentives to invest in new, more productive technological and organizational solutions. Thus, it affects both labour productivity and the total factor productivity growth [17].

Many research studies confirm that regulations affecting competitive pressure in the economy are often related to regulations influencing effectiveness of labour markets in the reallocation of human capital. Gust and Marquez [18] analyzed a panel of 13 industrial countries in the 1990s to find the sources of divergence in productivity growth. These authors argue that the burdensome regulatory environment and in particular regulations affecting labour markets were responsible for lower productivity growth in many industrial countries. Kuder [19] analysed the role of institutional factors in determining the growth rate of the United States economy in the years 1979-2001, where the main objective of the research was pointing out the institutions which were affecting growth to the highest extent. Under the influence of Amble [20], she concentrated on the following institutional areas: labour market, financial market, education and R\&D. Her results indicated the most significant role of transformation of labour market arrangements, with special attention to institutional factors affecting the employment cost and the level of unionization in influencing long-term growth in the United States. The role of job protection regulations on productivity growth was also confirmed by Bassanini et al. [21]. They confirmed negative effects of mandatory dismissal regulations on productivity growth in the industries where layoff restrictions were more likely to be binding.

Finally, the role of financial system and its effectiveness in influencing growth has been one of the most explored research areas for last three decades [22, 23, and 24]. The direct relationship between financial development and productivity growth is related to efficient capital reallocation process that should enable to shift quickly capital from declining industries to those with high growth perspectives. Arizala et al. [25], in one of the bigger studies on 77 countries with data for 26 manufacturing industries in the years 1963-2002 confirmed a significant relationship between financial development and industry level TFP growth.

The next section is devoted to the problems and dilemmas of operationalizing and measuring framework for five institutional aspects described above.

\subsection{Quality of Institutions and its Measurement}

The concept of quality of institutions is currently considered as the core of institutional economics. Though, it is not easy to define and operationalize this term. Also, a vigorous discussion on the problem of distinction between policies 
and intuitions shows fundamental problems of institutional theory [26, 27]. In this context, it is very hard to question Voigt's statement that "only if institutions can be measured with a minimum degree of confidence are empirical statements such as 'institutions matter for y' credible” [27].

In order to define institutions, most of the new institutional economists accept the North's proposal, where "Institutions are humanly devised constraints that structure human interaction. They are made up of formal constraints (e.g., rules, laws, constitutions), informal constraints (e.g., norms of behaviour, convention, self-imposed codes of conduct), and their enforcement characteristics. Together they define the incentive structure of societies and specifically economies." [28].

The current paper concentrates on the quality of institutions that influence the speed of resources reallocation that are crucial for taking advantage of the global knowledge-based economy. The definition of quality itself is based on the framework of transaction costs theory in complex economies, which is currently considered as one of the core concepts in new institutional economics [see 1;29]. To remind shortly the definition of transaction costs, with regard to economic consequence of technological changes the transaction costs are not only the costs of coordinating the increasingly complex interdependent parts of an economy, but they are also the costs of enforcing agreements and making credible commitments across time and space, necessary to realize the potential of technology [29].

From the empirical perspective measuring quality of institutions, often also within transaction cost theory framework, is based on application of approximate measures, which are often based on the feelings of a given economic entity or group of economic actors. This naturally gives a high level of subjectivity to the process and creates features of institutions difficult to quantify [19]. It makes the issue of quality of institutions a multiple-criteria analysis problem, and in that way it is treated in the current article.

Practically in the case of international comparative empirical research, especially for application of quantitative methods, authors usually use indexes of institutional quality, which are based on the databases provided by international institutions and organizations such as World Bank, Fraser Institute, Heritage Foundation or World Economic Form [9; 30]. More specific discussion in this regard is given in Section 3.3.

Finally, before moving to the presentation of applied research methodology, it must be stressed that the empirical approach presented in this article, with the specific definition of the institutional aspects, is aimed at fulfilling the first institutions measurement objective given by Voigt [27], who argues that "measures of institutions should refer to specific institutions because aggregate measures such as 'the rule of law' are too bread and fuzzy to contain meaningful information". This objective resulted in application of two stage analytical levels in the current research and choice of modified TOPSIS method. 


\section{Research Methodology}

The objective of the current research is to provide multiple criteria analysis of the quality of institutions, where the assumption is made that not all the specific institutional factors have equal importance for the effectiveness of the whole system. In that case, two approaches are possible. First of all, application of weights based on the knowledge and previous expertise of the researcher is possible. The basic criticism of that approach relates to the consequences of arbitral choices and preferences of the researchers, which can result in possibilities of results manipulation. Then, one can apply formal statistical objective criteria, which are based on statistical characteristics of the variables used in the research. In the current research, the second option was applied. As a result, TOPSIS method based on entropy measure for objective weighting was applied in the current research.

In the next subsection of the paper specific information on data preparation and formal information criteria for variables selection was presented. Next, the applied method and data were described in details.

\subsection{Data Preparation and Formal Criteria for Variables Selection}

The first stage of every multiple-criteria analysis relates to selection of set of object $O_{\mathrm{i}}$ and the economic phenomena under consideration. Next, a subset of specific aspects $\left(Y_{1}, Y_{2}, \ldots, Y_{1}\right)$ for given economic phenomenon and a set of attributes (diagnostic variables) $X_{1}^{s}, X_{2}^{s}, \ldots, X_{k}^{s}$ for every aspect $Y_{\mathrm{s}}$ is determined.

After selection of attributes $X_{j}^{s}$ their character must be specified. The diagnostic variables are categorized as benefit variables or negative variables. For benefit variables $X_{j}^{s}$ for every two values $x_{i, j}^{s}, x_{k, j}^{s}$ that refer to objects $O_{\mathrm{i}}, O_{\mathrm{k}}$, the relation $x_{i, j}^{s}>x_{k, j}^{s} \rightarrow O_{i} \succ O_{k}$ is fulfilled, where $\succ$ means that object $O_{\mathrm{i}}$ is preferred to $O_{\mathrm{k}}$. Thus, a maximum value of variable is preferred. For negative variable $X_{j}^{s}$ for every two values $x_{i, j}^{s}, x_{k, j}^{s}$ that refer to objects $O_{i}, O_{k}$ the relation $x_{i, j}^{s}<x_{k, j}^{s} \rightarrow O_{i} \prec O_{k}$ is fulfilled, where $\prec$ means that object $O_{k}$ is preferred to object $O_{i}$. Thus, a minimum value of variable is preferred [5].

After preliminary selection of the diagnostic variables, which is based on the content related criteria and experience of a researcher, the second step of multiplecriteria analysis concentrates on a formal verification of variables information value based on formal/statistical criteria. For this purpose, taxonomic criteria of 
information value can be used [31]. The final diagnostic variables should fulfil three criteria, of which the first two ones are the most commonly applied [32;33]:

a) High level of variation - the final diagnostic variables should not be similar to each other in the sense of information on the objects, so the diagnostic variables should obtain at least a minimum level of variation. To evaluate the level of variation, coefficient of variation can be applied, which is given with Formula 1.

$$
V_{j}=\frac{s_{j}}{\overline{x_{j}}} \quad i=1,2, \ldots n
$$

Where $s_{j}$ is the standard deviation of $j$ variable; $\overline{x_{j}}$ is arithmetic mean of $j$ variable. The variables which do not fulfil a formal criterion, for example such as the minimum accepted value of $V_{j}=0,1$, are eliminated.

b) Level of correlation - the diagnostic variables should not be too highly correlated. High correlation of the variables leads to overlapping of information, thus some of the variables are redundant. For highly correlated diagnostic variables a Hellwig's parametric method can be applied, where the maximum acceptable value of correlation coefficient for potential variables can be set as $r=0,85$. This value can be set with application of formal criteria or is usually given at the researcher's discretion [31,33].

c) High information value - the final diagnostic variables should reach high values with difficulty. To evaluate the information values of the variables the skewness coefficient can be used. In the case of benefit variables, the distribution of the variable should be right-skewed. When it is left-skewed, it means that most of the objects relatively easily reach high values of the variable, thus it does not differentiate the objects significantly.

In the final step, the selected diagnostic variables should be normalised, and the negative variables should be transferred into benefit variables. As common practice in this process, the unitarisation method or standardization are applied $[34,35,36]$. As all the final diagnostic variables applied in the research were classified as benefit variables, a classic standardization procedure given with Formula 2 was used here. It allowed to obtain variables characterized with mean at the level 0 and variance that is equal to 1 .

$$
x_{i j t}:=\frac{x_{i j t}-\overline{x_{j t}}}{s_{j t}} \quad i=1,2, \ldots n, j=1,2, \ldots, p, t=1,2, . . l
$$

where $\overline{x_{j t}}$ and $s_{j t}$ are given with formulas 3 . 


$$
\begin{aligned}
\overline{x_{j t}}=\frac{1}{n} \sum_{i=1}^{n} x_{i j t}, \quad s_{j t} & =\sqrt{\frac{1}{n} \sum_{i=1}^{n}\left(x_{i j t}-\overline{x_{i j t}}\right)^{2}} \\
i & =1,2, \ldots n, j=1,2, \ldots, p, t=1,2, . . l
\end{aligned}
$$

\subsection{TOPSIS Based on Entropy Measure for Objective Weighting}

Technique for Order Preference by Similarity to Ideal Solution (TOPSIS) is a tool which is commonly applied for solving multiple criteria decision making problems (MCDM) [37, 38]. The method is based on the concept of ordering alternatives by similarity to an ideal solution. The TOPSIS methodology can be also effectively applied for description and evaluation of economic objects under consideration, not as it is in the case of MCDM for the procedure of choosing the best alternative $[5 ; 39,40,41]$.

After selection of a final set of diagnostic variables, which was described in the previous subsection, a synthetic measure of development of the phenomenon under research can be assessed. In the case of TOPSIS method it is defined as the similarity or relative closeness to the positive ideal solution. The synthetic measure enables to assess the development level of phenomenon for every object. The method allows assessing and comparing the current situation of the objects.

In the research, the modified TOPSIS method is proposed. This approach can be especially useful when there is a possibility to extract complex economic aspects which refer to a specific feature of the object. In the case of every aspect $Y_{s}$ for variables $X_{j t}^{s}$ the positive ideal solution $I_{s, j t}^{P}$ and negative ideal solution $I_{s, j t}^{N}$ are specified with equations 3 :

$$
I_{s, j t}^{P}=\max _{i} x_{i j t} \quad, I_{s, j t}^{N}=\min _{i} x_{i j t}
$$

In the case of every distinct aspect $Y_{\mathrm{s}}$ separation measures $D_{s, i t}^{P}$ from the positive ideal solution and $D_{s, i t}^{N}$ from negative ideal solution for every object $O_{\mathrm{i}}$ are calculated with equations 4 :

$$
\boldsymbol{D}_{s, i t}^{P}=\sqrt{\sum_{j=1}^{n}\left(x_{i j t}-I_{s, j t}^{P}\right)^{2}} \boldsymbol{D}_{s, i t}^{N}=\sqrt{\sum_{j=1}^{n}\left(x_{i j t}-I_{s, j t}^{N}\right)^{2}}
$$

The value of synthetic sub-index $R_{i t}^{s}$ that describes every chosen aspect $Y_{\mathrm{s}}$ for every $O_{\mathrm{i}}$ is obtained by combining the proximity to the positive ideal solution and the remoteness from the negative ideal solution. The sub-index is given with the equation (5). 
$R_{i t}^{S}=1-\frac{D_{s, i t}^{P}}{D_{s, i t}^{P}+D_{s, i t}^{N}}$

Relative closeness to the positive ideal solution is a normalized measure usually on scale of $0-1$, where its higher values indicate a higher level of development of the aspect $Y_{\mathrm{s}}$.

Final synthetic index $R_{\mathrm{it}}$ is calculated as the weighted arithmetic mean given with the equation (6).

$$
R_{i t}=\sum_{s=1}^{k} w_{s} R_{i t}^{s}(6)
$$

where $w_{\mathrm{s}}$ means weights for every aspect $Y_{\mathrm{s}}$ and the sum of weights equals to 1 .

In order to avoid the problem of arbitral choice of the values of weights or simplified assumption of equal weights, the idea of objective weights, which are based on the entropy weights, can be used [42, 43, 44]. In that case, the definition of Shannon entropy, which was developed and implemented in the information theory, is applied [45].

To assess a set of entropy weights $w_{s t}$ for variables $R_{i t}^{s}$ based on the entropy value in the first step the entropy value $e_{s t}$ is calculated (7) [42].

$$
e_{s t}=-\frac{1}{\ln (k)} \sum_{i=1}^{n} p_{i s t} \ln \left(p_{i s t}\right) \underset{(7) ; \text { where: }}{\bar{~}} p_{i s t}=\frac{R_{i t}^{s}}{\sum_{i=1}^{n} R_{i t}^{s}}
$$

Finally, entropy weights $w_{s t}$ with the equation 8 are obtained.

$$
w_{s t}=\frac{1-e_{s t}}{n-\sum_{s=1}^{k} e_{s t}}
$$

where the sum of entropy weights $w_{s t}$ is equal to 1 .

The assessing of the synthetic measure of development with TOPSIS method enables not only to order the objects, but it also allows to divide the objects into homogenous subsets (classes), which significantly simplifies the interpretation of the obtained results. For this purpose, the method of natural breaks (Jenks method) can be used. The natural breaks method is based on the idea of minimization of variance for objects from the chosen subsets and maximization of variance between the subsets $[46,5]$. 


\subsection{Empirical Data}

In order to choose the data bases, the following objectives were formulated: a) international comparative coverage; b) long-term data availability and its comparability in time, c) processing of the data with one methodology, d) finally, international recognition of the quality of the obtained data and the mythology of its processing. Based on these criteria, the data from detailed base provided by Fraser Institute, which is used for publications of the Economic Freedom of the World Annual Reports, was chosen [47].

Based on the first condition, the possibility of application of country-specific data from national sources has been excluded. Beside Fraser Institute database, there are also other international bases that fulfill the first, third and fourth criterion, such as Doing Business database prepared by the World Bank, Heritage Foundation data base for Index of Economic Freedom or World Economic Form data base for Global Competitiveness Report. All of them cover shorter timespans than the Fraser Institute database. Additionally, the big advantage of the Economic Freedom of the World data base is its breadth of its coverage and the multidimensionality of its definition.

\section{Results}

The current research was done for 25 European Union countries in the following years: 2000, 2005, 2010, 2015. Cyprus, Luxemburg and Malta were excluded from the research due to the specifics of their economies and lack of empirical data for some institutional variables. The period 2000-2015 was restricted by the availability of data. The five-year sub-periods were considered as long enough for implementation of formal changes, which can affect institutional variables. The institutional aspects with a sub-set of preliminary variables are given in Table 1.

Table 1

The vector of attributes and preliminary diagnostic variables

\begin{tabular}{|l|}
\hline$Y_{1}-$ formal regulations influencing entrepreneurship \\
\hline$X_{1}^{1}-$ Administrative requirements for entrepreneurs \\
\hline$X_{2}^{1}-$ Bureaucracy costs \\
\hline$X_{3}^{1}-$ The cost of starting business \\
\hline$X_{4}^{1}-$ Extra payments/bribes/favouritism \\
\hline$X_{5}^{1}-$ Licensing restrictions \\
\hline$X_{6}^{1}-$ Tax compliance \\
\hline
\end{tabular}




\begin{tabular}{|c|}
\hline$Y_{2}$ - effectiveness of juridical system in keeping \\
\hline$X_{1}^{2}-$ Judicial independence \\
\hline$X_{2}^{2}-$ Impartial courts \\
\hline$X_{3}^{2}-$ Protection of property rights \\
\hline$X_{4}^{2}-$ Integrity of the legal system \\
\hline$X_{5}^{2}-$ Legal enforcement of contracts \\
\hline$X_{6}^{2}-$ Regulatory restrictions on the sale of real property \\
\hline$X_{7}^{2}-$ Reliability of police \\
\hline$X_{8}^{2}-$ Business costs of crime \\
\hline$Y_{3}-$ regulations affecting competitive pressure \\
\hline$X_{1}^{3}-$ Mean tariff rate \\
\hline$X_{2}^{3}-$ Standard deviation of tariff rates \\
\hline$X_{3}^{3}-$ Non-tariff trade barriers \\
\hline$X_{4}^{3}-$ Compliance costs of importing and exporting \\
\hline$X_{5}^{3}-$ Foreign ownership/investment restrictions \\
\hline$X_{6}^{3}-$ Capital controls \\
\hline$Y_{4}-$ effectiveness of labour markets \\
\hline$X_{1}^{4}-$ Hiring regulations and minimum wage \\
\hline$X_{2}^{4}-$ Hiring and firing regulations \\
\hline$X_{3}^{4}-$ Centralized collective bargaining \\
\hline$X_{5}^{4}-$ Hours regulations \\
\hline$X_{6}^{4}-$ Mandated cost of worker dismissal \\
\hline$Y_{5}-$ financial markets institutions as a stimulator \\
\hline$X_{1}^{5}-$ Ownership of banks \\
\hline$X_{2}^{5}-$ Private sector credit \\
\hline
\end{tabular}

At the first stage, completeness of data for the preliminary variables was verified. The data on Reliability of police and Business costs of crime are not available for the years 2000-2004. The data on variable Licensing restrictions are not available in the years 2000-2003. The three variables were removed from the study.

Table 2 presents the result for the quality information criteria analysis, which is based on the required minimum level of variable variation. The criterion of minimum value of $V_{j t}=0.1$ was applied for all the years 2000-2015. Based on the obtained results, $X_{3}^{1}, X_{1}^{3}, X_{2}^{3}$ were removed from the set of diagnostic variables. The value of $V_{j}$ for $X_{3}^{3}$ in the year 2013 was close to 0.09 ; for $X_{4}^{3}$ in the years 2000-2003 and 2010-2013 it was higher than 0,07, and for $X_{2}^{5}$ in the years 2007- 
2009 it was higher than 0,08 . As these variables do not reach the minimum criteria only in the case of the chosen years, and additionally the given values of $V_{j t}$ can be considered as close to the benchmark value, the variables were left in set of diagnostic variables, which were analyzed with correlation criteria.

The conducted analysis of variables variation provided interesting information with regard to $X_{3}^{1}$. In the analyzed period, there is a tendency to unify and reduce the cost of starting business in the EU countries. In the year 2000 the average value for this variable was equal to 8,63, in the year 2005 it was 9.03, in 2010 it was 9.46 , and finally in the year 2015 it was 9,62 , where 10 is the highest possible value of the variable. In the years 2000-2003 the value of $V_{j t}$ was higher than 0,09, then in the years 2004 to 2015 it was reduced from the level 0,06 to about 0,02. These factors confirm a common understanding of negative consequences of higher transaction costs with regard to the cost of starting business.

Table 2 provides specific information on variables that do not fulfil the conditions for minimum level of variation.

Table 2

Variables that do not fulfil the conditions for minimum level of variation

\begin{tabular}{|l|l|}
\hline \multicolumn{1}{|c|}{ Variable } & \multicolumn{1}{|c|}{ The years where $\mathbf{V}<\mathbf{0 . 1}$} \\
\hline$X_{3}^{1}-$ The cost of starting business & $2000-2015$ \\
\hline$X_{3}^{3}-$ Non-tariff trade barriers & 2013 \\
\hline$X_{1}^{3}-$ Mean tariff rate & $2000-2001,2004-2015$ \\
\hline$X_{2}^{3}-$ Standard deviation of tariff rates & $2005-2015$ \\
\hline$X_{4}^{3}-$ Compliance costs of importing and exporting & $2000-2003,2010-2015$ \\
\hline$X_{2}^{5}-$ Private sector credit & $2007-2009$ \\
\hline
\end{tabular}

Source: own estimation based on data base from Fraser Institute

At the next stage, the analysis of correlation between variables was conducted. After application of Hellwig's parametric method, three variables were removed from the final set of diagnostic variables $X_{4}^{1}, X_{1}^{2}$ and $X_{2}^{2}$.

The current Fraser Institute data base is created for 159 countries. From that perspective, the European Union countries can be considered as a relatively homogenous group of developed countries, which tend to obtain relatively good results in many aspects. It is also actual with regard to quality of institutional factors. It is natural that due to the methodology of data base preparation, in the case of many aspects the condition of reaching right-skewed distribution for befit variables is not fulfilled. Due to the dominance of the merit criteria over formal statistical requirements this condition is not applied in the current research. The final set of diagnostic variables applied for the research is given in Table 3. 
Table 3

The vector of attributes and final diagnostic variables applied for TOPSIS method

\begin{tabular}{|l|}
\hline$Y_{1}$ - formal regulations influencing entrepreneurship $X_{1}^{1}, X_{2}^{1}, X_{6}^{1}$ \\
\hline $\begin{array}{l}Y_{2} \text { - effectiveness of juridical system in keeping low level of transaction costs and supporting } \\
\text { effectiveness of market mechanism } X_{3}^{2}, X_{4}^{2}, X_{5}^{2}, X_{6}^{2}\end{array}$ \\
\hline$Y_{3}$ - regulations affecting competitive pressure $X_{3}^{3}, X_{4}^{3}, X_{5}^{3}, X_{6}^{3}$ \\
\hline$Y_{4}$ - effectiveness of labour markets $X_{1}^{4}, X_{2}^{4}, X_{3}^{4}, X_{5}^{4}, X_{6}^{4}$ \\
\hline$Y_{5}$ - financial markets institutions as a stimulator of development of enterprises with high \\
growth potential $X_{1}^{5}, X_{2}^{5}$
\end{tabular}

Source: own estimation based on data base from Fraser Institute

Table 4

The waights for institutional aspects in the years 2000, 2005, 2010, 2015

\begin{tabular}{|l|r|r|r|r|}
\hline Institutional Aspect & $\mathbf{2 0 0 0}$ & $\mathbf{2 0 0 5}$ & $\mathbf{2 0 1 0}$ & $\mathbf{2 0 1 5}$ \\
\hline $\mathrm{Y}_{1}$ & $9.54 \%$ & $23.15 \%$ & $8.70 \%$ & $18.96 \%$ \\
\hline $\mathrm{Y}_{2}$ & $22.73 \%$ & $18.42 \%$ & $19.34 \%$ & $30.51 \%$ \\
\hline $\mathrm{Y}_{3}$ & $24.47 \%$ & $26.70 \%$ & $26.29 \%$ & $14.31 \%$ \\
\hline $\mathrm{Y}_{4}$ & $29.56 \%$ & $25.09 \%$ & $25.23 \%$ & $27.49 \%$ \\
\hline $\mathrm{Y}_{5}$ & $13.70 \%$ & $6.63 \%$ & $20.45 \%$ & $8.73 \%$ \\
\hline
\end{tabular}

Source: own estimation based on data base from Fraser Institute

The values of weights obtained with application of entropy measure for objective weighting are given in Table 4 . The average values of obtained weights for all the attributes in the analysed period indicate that there are two subsets here. The highest average value for weights for all four years was assessed for effectiveness of labour markets $26,84 \%$, then the quality of juridical system and regulations affecting competitive pressure obtained $22,75 \%$ and $22,94 \%$, whereas the regulations on entrepreneurship and financial markets obtained 15,09\% and $12.38 \%$ respectively. That obtained outcome is to a high extent consistent with the previous studies on the importance of institutional factors in forming growth incentives, which has been also already given in the literature review.

The final results with ranking and grouping of the countries into four classes based on natural breaks method are given in Table 5 and Figure 1. In the first class, the countries with the highest value of institutional quality synthetic measure are placed, whereas in the fourth one the economies with its lowest value are found. The obtained ranking and grouping confirm the long-term structural institutional divergence in the European Union, where the historically determined differences between Eastern and Western European countries are not so valid anymore. On the other hand, the research confirms long term institutional disparities between Northern and Southern European economies, which also significantly contributed to economic instability of the European Union during last global financial crisis. 
Table 5

Ranking and grouping of the EU countries based on quality of institutions

\begin{tabular}{|c|c|c|c|c|c|c|c|c|c|c|c|c|}
\hline \multirow[b]{2}{*}{ Countries } & \multicolumn{3}{|c|}{2000} & \multicolumn{3}{|c|}{2005} & \multicolumn{3}{|c|}{2010} & \multicolumn{3}{|c|}{2015} \\
\hline & $\mathrm{R}_{\mathrm{it}}$ & Rank & Class & $\mathrm{R}_{\mathrm{it}}$ & Rank & Class & $\mathrm{R}_{\mathrm{it}}$ & Rank & Class & $\mathrm{R}_{\mathrm{it}}$ & Rank & Class \\
\hline Denmark & 0.7759 & 2 & 1 & 0.7657 & 1 & 1 & 0.7600 & 1 & 1 & 0.7441 & 1 & 1 \\
\hline Ireland & 0.6335 & 8 & 2 & 0.6773 & 4 & 1 & 0.6170 & 11 & 2 & 0.7300 & 2 & 1 \\
\hline United Kingdom & 0.7930 & 1 & 1 & 0.7105 & 2 & 1 & 0.6859 & 4 & 1 & 0.6988 & 3 & 1 \\
\hline Netherlands & 0.6900 & 5 & 2 & 0.6130 & 9 & 2 & 0.6532 & 6 & 2 & 0.6945 & 4 & 1 \\
\hline Estonia & 0.6522 & 6 & 2 & 0.6545 & 5 & 2 & 0.7160 & 2 & 1 & 0.6901 & 5 & 1 \\
\hline Finland & 0.7065 & 3 & 1 & 0.6940 & 3 & 1 & 0.7091 & 3 & 1 & 0.6766 & 6 & 2 \\
\hline Sweden & 0.6404 & 7 & 2 & 0.6195 & 7 & 2 & 0.6600 & 5 & 2 & 0.6718 & 7 & 2 \\
\hline Latvia & 0.5982 & 13 & 2 & 0.6026 & 10 & 2 & 0.6373 & 8 & 2 & 0.6668 & 8 & 2 \\
\hline Austria & 0.6939 & 4 & 1 & 0.6247 & 6 & 2 & 0.6421 & 7 & 2 & 0.6420 & 9 & 2 \\
\hline Lithuania & 0.5504 & 16 & 3 & 0.5562 & 12 & 3 & 0.5223 & 20 & 3 & 0.6403 & 10 & 2 \\
\hline Germany & 0.6004 & 12 & 2 & 0.5478 & 13 & 3 & 0.5611 & 16 & 3 & 0.6213 & 11 & 2 \\
\hline Czech Rep. & 0.5345 & 19 & 3 & 0.4721 & 20 & 4 & 0.5730 & 15 & 3 & 0.6112 & 12 & 3 \\
\hline Belgium & 0.6328 & 9 & 2 & 0.5829 & 11 & 2 & 0.6279 & 9 & 2 & 0.5961 & 13 & 3 \\
\hline Romania & 0.5399 & 17 & 3 & 0.5361 & 15 & 3 & 0.5791 & 14 & 3 & 0.5879 & 14 & 3 \\
\hline France & 0.6295 & 10 & 2 & 0.5468 & 14 & 3 & 0.5950 & 12 & 2 & 0.5826 & 15 & 3 \\
\hline Spain & 0.6034 & 11 & 2 & 0.5321 & 16 & 3 & 0.5254 & 19 & 3 & 0.5825 & 16 & 3 \\
\hline Portugal & 0.5347 & 18 & 3 & 0.4528 & 21 & 4 & 0.4783 & 23 & 4 & 0.5781 & 17 & 3 \\
\hline Poland & 0.4256 & 25 & 4 & 0.4309 & 24 & 4 & 0.4978 & 22 & 3 & 0.5714 & 18 & 3 \\
\hline Hungary & 0.5870 & 14 & 2 & 0.5266 & 17 & 3 & 0.6203 & 10 & 2 & 0.5679 & 19 & 3 \\
\hline Slovak Rep & 0.5088 & 21 & 3 & 0.6180 & 8 & 2 & 0.5832 & 13 & 3 & 0.5579 & 20 & 3 \\
\hline Slovenia & 0.4798 & 23 & 4 & 0.4488 & 22 & 4 & 0.4551 & 24 & 4 & 0.5159 & 21 & 4 \\
\hline Bulgaria & 0.5220 & 20 & 3 & 0.4180 & 25 & 4 & 0.5595 & 17 & 3 & 0.5132 & 22 & 4 \\
\hline Croatia & 0.4418 & 24 & 4 & 0.4722 & 19 & 4 & 0.5261 & 18 & 3 & 0.5122 & 23 & 4 \\
\hline Italy & 0.5591 & 15 & 3 & 0.4747 & 18 & 4 & 0.5206 & 21 & 3 & 0.5119 & 24 & 4 \\
\hline Greece & 0.4925 & 22 & 3 & 0.4341 & 23 & 4 & 0.3834 & 25 & 4 & 0.4729 & 25 & 4 \\
\hline
\end{tabular}

Source: own estimation based on data base from Fraser Institute
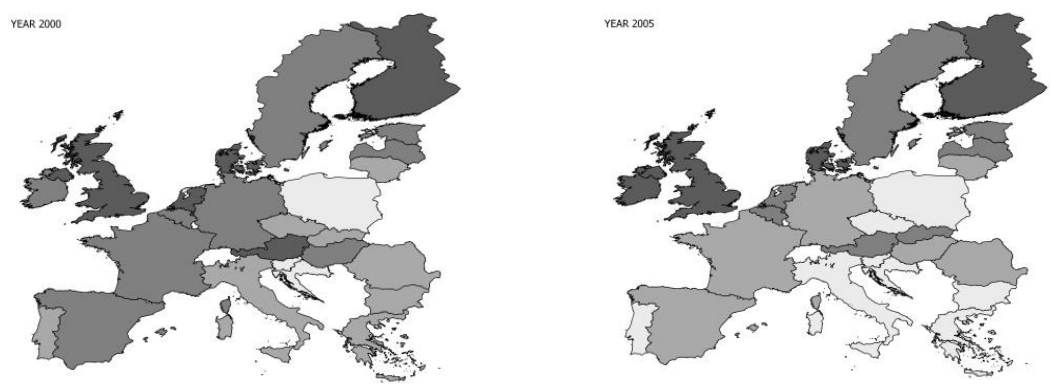


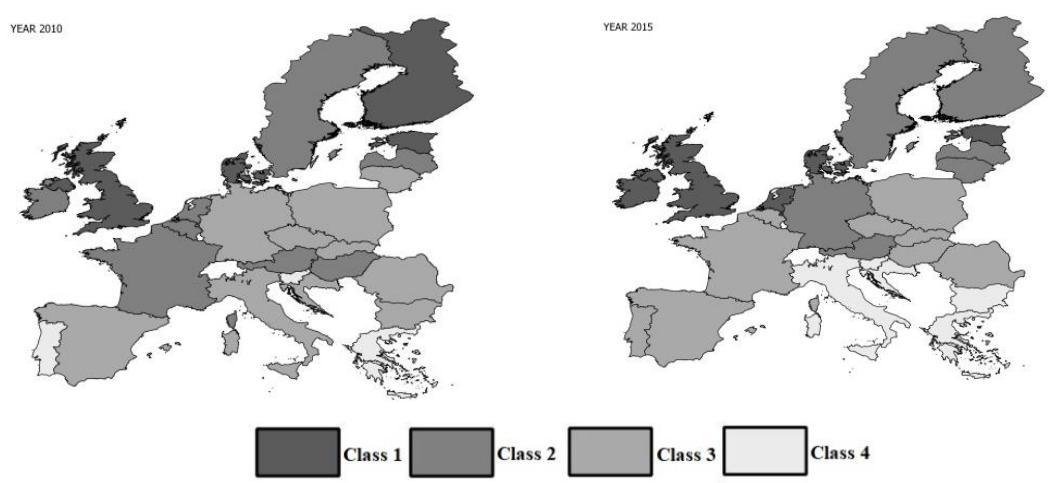

Figure 1

Grouping of the EU countries based on quality of institutions

Source: own estimation based on data base from Fraser Institute

So, throughout the whole period under research Scandinavian economies with Ireland and the United Kingdom are the leaders. Then, there is the group of the Central European member states, which can be compared with regard to obtained relative value of measure of institutional quality to such economic powers as Germany and France. This can be especially seen in the last year of the study. Finally, with the exception of Romania, which obtains relatively good results, we have the "latest new member" states such as Bulgaria, Croatia and, finally, Southern European countries, such as Italy and Greece.

\section{Discussion}

The current research is consistent to a high extent with previous studies of the Author [5], where the assumption on equal weights with regard to institutional aspects was taken, and contributions of other researchers in the field, which were devoted to multiple-criteria analysis of institutional factors in the EU countries. But it must be stressed that most of these other studies were concentrated on more widely defined institutional factors not always directly relating to the knowledgebased economy and the level of international competitiveness [48, 49, 50, 30, 33]. That result can be interpreted in favour of the new institutional economics postulates, in spite of the variety of approaches to defining institutions and variety of methodologies for their quantifying there is still one big picture with a common message, where the economic success is directly related not only to good macroeconomic policies, but also effective reforming of institutional economic order. What is important here, this factor cannot be only attributed to developing countries, but it is also actual in regard to developed economies that currently must face the challenges of the global knowledge-based economy. 
From the policy guidelines perspective, when one looks in detail at the obtained rankings, especially interesting results can be seen in the case of the Baltic countries and other Central European economies, such as the Czech Republic, Hungary and Poland. During the 15 years under investigation, the region has significantly improved its relative institutional quality. In that group, the case of Estonia is especially interesting, as in the year 2010 and 2015 the country could be found in the first class of economies with the highest value of synthetic measure of institutional quality. What is more, in the last year of the research it was even rated higher than Finland and Sweden. The improvements of relative positions were also obtained by Latvia and Lithuania. The success of Estonia is often given as a case of small and opened economy that on the one hand, is easy to reform due to its size, but on the other hand, from the perspective of informal institutions is quite close to Scandinavian economies that additionally supports the reforming process. However, an interesting example of institutional changes for a relatively big economy can be seen in the case of Poland, which started with the lowest value of synthetic measure in the year 2000. Since the year 2010, the country has been placed in the third class, with the value of institutional quality measure close to such countries as France, Spain and Portugal. Also, relatively high positions of Romania should be stressed here.

On the other hand, one can point to two negative benchmark countries: Greece and Italy, where the case of the former one is especially significant. In the year 2000 , Italy was rated in the third class at 15 th position in the ranking. During the next years the relative position of the country was worse, which indicates that other economies have been much more effective at improving their institutional systems with regard to the knowledge-based economy requirements.

\section{Conclusions}

The objective of the article was to conduct the research on the quality of institutions in the context of knowledge-based economy requirements, where the phenomenon was considered as a multiple-criteria subject of the analysis. In the study the common assumption on equal importance of all institutional aspects was abandoned and the modified TOPSIS method based on entropy measure for objective weighting was applied.

From a policy perspective the current research confirms the fundamental problems of the European Union in regard to institutional disparities between Northern and Southern European countries, which have threatened the stability of the European economy during last global financial crisis. On the other hand, from the perspective of Central Europe it shows the cases of good institutional reforms in the Baltic countries with Estonia as a leader of the group, which can be considered as a positive benchmark for the whole region.

The current study is a novel approach, which contributes to institutional economics and can be used in research in growth determinants in the European Union economies. Its most important value added to the field is related to: 
1) Theoretical contribution - in recent years, most of the research related to institutional growth determinants have concentrated on the developing economies, where a relatively wide range of formal and informal institutions are analysed. On the other hand, current research concentrates on relatively developed countries and institutions that play a crucial role in the process of quick and effective reallocation of resources under conditions of the knowledge-based economy. For this purpose, a multivariate measure of the quality of institutions for developed countries was proposed.

2) Methodological approach - in the research, an application of multiple-criteria analysis approach is proposed, which is currently considered as an effective method with regard to measurement and description of phenomena which are multivariate, latent and difficult to measure. In international comparative research, in order to keep objectivity of the research, a standard assumption tends to be made that all the factors (variables) taken into consideration have equal importance and influence equally the phenomenon under investigation. In the case of the current research this assumption was abandoned. In order to avoid arbitral decisions in the evaluation process, objective weights were applied based on entropy measure for objective weighting. If it is not the first application of the method in institutional economics comparative research, it can be stated that the methodology is not applied as a standard quantitative tools in the field.

3) Practical value - the current research has a great importance for policy makers in the European Union countries in general, but it is of special value for decision makers in Central European economies, who face the problem of closing the development gap and building conditions, which will support these economies in the process of avoiding the middle income trap. Based on the modernisation experiences of the countries that avoided the middle income trap, the role of an institutional system is of the highest importance in this process.

The main limitation of the current research relates to the selection of diagnostic variables and data availability. In the case of every multiple-criteria analysis, the first step of the research - the decomposition of the phenomenon on given aspects and the selection of preliminary variables is always based on an arbitral expertise decision of a researcher. Then, in the case of longer-term research, quantitative analysis is directly restricted by the availability of data and their quality with regard to description of a given phenomenon.

The current article is the first step of the research which concentrates on the role of institutional factors in supporting long-term growth in Central European countries and their significance in avoiding the middle income trap. As a result, in the next step the research will be done for all the years of 2000-2015 with different assumptions with regard to weights for given institutional aspects, which will enable to obtain time series applicable for econometric analysis. Then, the time series will be used in the research on the institutional growth determinants in 
Central European economies and their possible contribution to avoid the middle income trap.

\section{References}

[1] Williamson, O. E. (1985) The Economic Institutions of Capitalism. Firms, Markets, Relational Contracting. Macmilllan

[2] North, D. C. (1990) Institutions, Institutional Change and Economic Performance. New York: Cambridge University Press

[3] Rodrik, D (2008) One Economics, Many Recipes: Globalization, Institutions, and Economic Growth. Princeton, NJ: Princeton University Press

[4] Rodrik, D, McMillan, M, \& Sepulveda, C (Eds) (2017) Structural Change, Fundamentals, and Growth: A Framework and Case Studies. Washington, DC: International Food Policy Research Institute

[5] Balcerzak, A. P., \& Pietrzak, M. B. (2016) Quality of Institutions for Knowledge-based Economy within New Institutional Economics Framework. Multiple Criteria Decision Analysis for European Countries in the Years 2000-2013. Economics \& Sociology, 9(4), pp. 66-81, doi: 10.14254/2071-789X.2016/9-4/4

[6] Acemoglu, D., Johnson, S., \& Robinson, J. A. (2001) The Colonial Origins Of Comparative Development: An Empirical Investigation. American Economic Review, 91(5), 1369-1401

[7] Acemoglu, D., Johnson, S., \& Robinson, J. A. (2002) Reversal Of Fortune: Geography And Institutions In The Making Of The Modern World Income Distribution. Quarterly Journal of Economics, 107(4), pp. 1231-1294

[8] Rodrik, D. (1999) Where Did All The Growth Go? Journal of Economic Growth, 4(4), pp. 385-412

[9] Carmignani, F. (2009) The Distributive Effects of Institutional Quality When Government Stability is Endogenous. European Journal of Political Economy, 25(4) 409-421, doi: 10.1016/j.ejpoleco.2009.03.003

[10] OECD (2001) The New Economy. Beyond the Hype. Paris: OECD

[11] Davidsson, P. \& Henrekson, M. (2002) Determinants of the Prevalence of Start-ups and High-Growth Firms Magnus Henrekson. Small Business Economics, 19, pp. 81-104

[12] Bosma, N., Content, J., Sanders, M., \&, Stam, E. (2018) Institutions, entrepreneurship, and economic growth in Europe. Small Business Economics, 51(2) pp. 483-499, doi: 10.1007/s11187-018-0012-x

[13] Ignatov, A. (2018) Entrepreneurial Innovation: the European Union Perspective. Review of Economic Perspectives, 18(2), pp. 137-154, doi: 10.2478/revecp-2018-0008 
[14] Aparicio, S., Urbano, D., \& Audretsch, D. (2016) Institutional Factors, Opportunity Entrepreneurship and Economic Growth: Panel Data Evidence. Technological Forecasting and Social Change, 102, pp. 45-61, doi: 10.1016/j.techfore.2015.04.006

[15] Cusatelli, C., \& Giacalone, C. (2014) Evaluation Indices of the Judicial System and ICT Developments in Civil Procedure. Proceedia Economics and Finance, 17, pp. 113-120, doi: 10.1016/S2212-5671(14)00885-5

[16] Lorizio, M., \& Gurrieri, A. R. (2014) Efficiency of Justice and Economic Systems. Proceedia Economics and Finance, 17, pp. 104112, doi: 10.1016/S2212-5671(14)00885-3

[17] Bassanini, A., \& Scarpetta, S. (2002) Growth, Technological Change, and ICT Diffusion: Recent Evidence from OECD Countries. Oxford Review of Economic Policy, 18(3), pp. 324-344, doi: 10.1093/oxrep/18.3.324

[18] Gust, C., \& Marquez, J. (2002) International Comparisons of Productivity Growth: The Role of Information Technology and Regulatory Practices. International Finance Discussion Papers, Board of Governors of the Federal Reserve Systems, No. 727, doi: 10.2139/ssrn.314200

[19] Kuder, D. (2015) Impact of Institutional Factors on Economic Growth in the United States in the Years 1979-2007, Oeconomia Copernicana, 6(1) pp. 137-159, doi: 10.12775/OeC. 2015.008

[20] Amable, B. (2003) The Diversity of Modern Capitalism. Oxford-New York: Oxford University Press

[21] Bassanini, A., Nunziata, L., \& Danielle Venn (2009) Job Protection Legislation and Productivity Growth in OECD Countries. Economic Policy, 24(58) pp. 349-402, doi: 10.1111/j.1468-0327.2009.00221.x

[22] Pagano, M. (1993) Financial Markes and Growth. European Economic Review, 37, pp. 613-622

[23] Brzozowski, M. (2018) Credit Volatility and Productivity Growth. Equilibrium. Quarterly Journal of Economics and Economic Policy, 13(2) pp. 215-232, doi: 10.24136/eq.2018.011

[24] Pietrucha, J., \& Acedański, J. (2017) Financial Depth and Post-2008 Change of GDP. Equilibrium. Quarterly Journal of Economics and Economic Policy, 12(3) pp. 469-482, doi: 10.24136/eq.v12i3.25

[25] Arizala, F., Cavallo, E., \& Galindo, A. (2009) Financial Development and TFP Growth: Cross-country and Indsutry-level Evidence. Inter-American Devleopment Bank. Working Paper, 682, doi: /10.2139/ssrn.1395716

[26] Glaeser, E. L., La Porta, R., Lopez-de-Silanes, F., \& Shleifer, A., (2004) Do Instituions Cause Growth? Journal of Economic Growth, 9(3) pp. 271-303, doi: 10.1023/B:JOEG.0000038933.16398.ed 
[27] Voight, S. (2013) How (not) to Measure Instituons. Journal of Institutional Economics, 9(1) pp. 1-26, doi: $10.1017 / \mathrm{S} 1744137412000148$

[28] North, D. C. (1994) Economic Performance Through Time. American Economic Review, 84(3) pp. 359-368

[29] North, D.C. (1993) Institutions, Transaction Costs and Productivity in the Long Run. Economic History, 9309004, EconWPA, Retrieved form http://econwpa.repec.org/eps/eh/papers/9309/9309004.pdf

[30] Żelazny, R., \& Pietrucha, J. (2017) Measuring Innovation and Institution: The Creative Economy Index. Equilibrium. Quarterly Journal of Economics and Economic Policy, 12(1) pp. 43-62, doi: 10.24136/eq.v12i1.3

[31] Hellwig, Z. (1972) On the Optimal Choice of Predictors. In Z. Gostkowski (Ed.). Towards a System of Human Capital Resources Indicators for Less Developed Countries. Papers Prepared for a UNESCO Research Project. Wrocław: Ossolineum, Polish Academy of Sciences Press, pp. 69-90

[32] Balcerzak, A. P. (2016) Technological Potential of European Economy. Proposition of Measurement with Application of Multiple Criteria Decision Analysis. Montenegrin Journal of Economics, 12(3) pp. 7-17, doi: $10.14254 / 1800-5845.2016 / 12-3 / 1$

[33] Cheba, K., \& Szopik-Depczyńska, K. (2017) Multidimensional Comparative Analysis of the Competitive Capacity of the European Union Countries and Geographical Regions. Oeconomia Copernicana, 8(4) pp. 487-504, doi: 10.24136/oc.v8i4.3

[34] Kukuła, K., \& Bogocz, D. (2014) Zero Unitarization Method and Its Application in Ranking Research in Agriculture. Economic and Regional Studies, 7(3) pp. 5-13

[35] Bartkowiak-Bakun, N. (2017) The Diversity of Socioeconomic Development of Rural Areas in Poland in The Western Borderland and the Problem of Post-state Farm Localities. Oeconomia Copernicana, 8(3), pp. 417-432, doi: 10.24136/oc.v8i3.26

[36] Wierzbicka, W. (2018) Information Infrastructure as a Pillar of the Knowledge-Based Economy — an Analysis of Regional Differentiation in Poland. Equilibrium. Quarterly Journal of Economics and Economic Policy, 13(1) pp. 123-139, doi: 10.24136/eq.2018.007

[37] Hwang, C. L., \& Yoon, K. (1981) Multiple Attribute Decision Making: Methods and Applications. Heidelberg: Springer. doi: 10.1007/978-3-64248318-9

[38] Yoon, K. P., \& Hwang, C. L. (1995) Multiple Attribute Decision Making: An Introduction. Thousand Oaks: CA Sage Pub 
[39] Pietrzak, M. B. (2016) The Problem of the Inclusion of Spatial Dependence Within the TOPSIS Method. Montenegrin Journal of Economics, 12(3) pp. 69-86, doi: 10.14254/1800-5845.2016/12-3/5

[40] Pietrzak, M. B, \& Ziemkiewicz, B. (2018) Multiple Criteria Analysis of Digital Economy in the European Union Countries. In M. Reiff \& P. Gezik (Eds.) Proceedings of the International Scientific Conference Quantitative Methods in Economics Multiple Criteria Decision Making XIX. Trenčianske Teplice: Letra Edu, pp. 283-290

[41] Pietrzak, M. B, \& Ziemkiewicz, B. (2018) Multiple Criteria Analysis of Digital Economy in the European Union Countries. In M. Reiff \& P. Gezik (Eds.). Proceedings of the International Scientific Conference Quantitative Methods in Economics Multiple Criteria Decision Making XIX. Trenčianske Teplice: Letra Edu, pp. 283-290

[42] Wang, T. C., \& Lee, H. D. (2009) Developing a Fuzzy TOPSIS Approach Based On Subjective Weights and Objective Eeights. Expert Systems with Applications, 36(5) pp. 8980-8985

[43] Shemshadi, A., Shirazi, H., Toreihi, M.,. \& Tarokh, M. J. (2011) A Fuzzy VIKOR Method for Supplier Selection Based on Entropy Measure for Objective Weighting. Expert Systems with Applications, 38(10) pp. 1216012167

[44] Balcerzak, A. P. (2017) Digital Economy in Czech Republic, Slovakia and Hungary. Measurement with TOPSIS Based on Entropy Measure for Objective Weighting. In T. Loster \& T. Pavelka (Eds.) The $11^{\text {th }}$ International Days of Statistics and Economics. Conference Proceedings. September 8-10, 2016, Prague: Libuse Macakova, Melandrium, 49-57

[45] Shannon, C. E., \& Weaver, W. (1947) The Mathematical Theory of Communication. Urbana: The University of Illinois Press

[46] Jenks, G. F. (1967) The Data Model Concept in Statistical Mapping, International Yearbook of Cartography, 7, pp. 186-190

[47] Gwartney, J., Lawson, R., \& Hall, J. (2017) Economic Freedom of the World: 2017 Annual Report. Fraser Institute. Retrieved form https://www.fraserinstitute.org/studies/economic-freedom

[48] Jantoń-Drozdowska, E., \& Majewska, M. (2016) Investment attractiveness of Central and Eastern European countries in the light of new locational advantages development. Equilibrium. Quarterly Journal of Economics and Economic Policy, 11(1), 97-119, doi: 10.12775/EQUIL.2016.005

[49] Roszko-Wójtowicz, E., \& Białek, J. (2017) Evaluation of the EU countries' innovative potential - multivariate approach. Statistics in Transition new series, 18(1) pp. 167-180

[50] Kruk, H., \& Waśniewska, A. (2017) Application of the Perkal Method for Assessing Competitiveness of the Countries of Central and Eastern Europe. Oeconomia Copernicana, 8(3) pp. 337-352, doi: 10.24136/oc.v8i3.21 